\title{
Evaluating the introduction of team-based learning in a pharmacy consultation skills module
}

\author{
Simon Tweddell \\ University of Bradford, Bradford, United Kingdom
}

\section{Keywords}

Team-based Learning

Active and Collaborative Learning

Curriculum Design

\section{Correspondence}

Dr Simon Tweddell

Senior Lecturer in Pharmacy Practice

Bradford School of Pharmacy and

Medical Sciences

University of Bradford

Bradford

BD7 1DP

United Kingdom

s.j.tweddell@bradford.ac.uk

\begin{abstract}
The learning and teaching strategy for a pharmacy consultation skills module was changed to Team-Based Learning (TBL) with the aim of motivating students to engage with course material pre-class and take deeper approaches to learning during class. Results from administering a validated TBL instrument suggests that students are more accountable and are satisfied with and have preference for TBL over traditional methods. Exam results show a $13 \%$ improvement in mean end-ofyear examinations compared with pre-TBL results. Thematic analysis of written comments on the module evaluation survey suggest that they enjoyed learning using TBL and found it more engaging, stimulating and more effective for their learning; however, it could be improved through better management of workshop timings and more effective facilitation of discussion. TBL appears to have potential as a pedagogic approach in pharmacy education.
\end{abstract}

\section{Introduction}

The programme team at University of Bradford introduced a new consultation skills module to the undergraduate Masters of Pharmacy (M.Pharm.) programme in 2008 to develop knowledge and understanding of minor ailments and skills to consult with patients. The consultation skills module received positive feedback from students and assessment results were good, relative to other modules at that stage. However, the module team felt that some students did not prepare adequately for workshops and were taking surface approaches to learning by not engaging with the subject content until close to the assessment. Workshops that were designed for application of knowledge learned in lectures were increasingly being used for content delivery. Students were not engaging effectively in the preworkshop activities which were designed to prepare them for the workshops, which focused on application of knowledge and development of higher-level thinking skills.
Definitions of student engagement vary across the higher education (HE) sector and there are differing opinions as to who is responsible for student engagement. The Higher Education Funding Council for England's (HEFCE) definition suggests that the responsibility lies with HE providers as 'the process whereby institutions and sector bodies make deliberate attempts to involve and empower students in the process of shaping the learning experience' (HEFCE, 2008). This could occur at different levels in the same institution. For example at an institutional level the Higher Education Institution (HEI) may engage students to enhance the collective learning experiences; these could include student representation, student feedback, and student partnerships. At programme level, academics design specific learning, teaching and assessment activities to enhance the engagement of individual students in their own learning (Little et al., 2009). However Hu and Kuh place the onus on individual students, defining engagement as 'the 
quality of effort students themselves devote to educationally purposeful activities that contribute directly to desired outcomes' (Hu \& Kuh, 2002: p.555). Kuh, however, later refines this view by arguing that it is responsibility of the student and $\mathrm{HEI}$ to engage students, defining engagement as 'the time and effort students devote to activities that are empirically linked to desired outcomes of college and what institutions do to induce students to participate in these activities' (Kuh, 2009: p. 683).

Coates bases the concept of student engagement on the constructivist assumption that learning is influenced by how an individual participates in 'educational purposeful activities' but also relies on institutions providing the 'conditions, opportunities and expectations' to engage. However, Coates states that ultimately it is the learner that is the agent in engagement (Coates, 2005). There is little doubt that positive engagement with educationally purposeful activities, whether this is in-class or selfdirected out-of-class, has shown to lead to learning (Coates, 2005). In pharmacy, educational research shows a negative correlation between the numbers of hours of missed classes and student performance, with low performers significantly more likely to believe that classes did not benefit them and therefore suggesting disengaged students (Hidayat et al., 2012).

Fredricks, Blumenfeld and Paris (2004), identify three dimensions of student engagement, albeit in school children:

1. Behavioural engagement: where students comply with behavioural norms, attend classes, follow the rules, and are not disruptive. Students contribute towards class discussions and participate in learning and academic activities.

2. Emotional engagement: this involves affective reactions such as demonstrating interest, happiness, enjoyment, or a sense of belonging.

3. Cognitive engagement: where students are invested in their learning, go the extra mile, and who seek out and enjoy challenges.

Trowler (2010) suggests that engagement is a continuum, with positive behaviours that are productive or constructive at one end, and negative behaviours that can be disruptive, obstructive or counter-productive at the other. Trowler argues that between these poles could be a range or gulf of non-engagement such as withdrawal or apathy. She goes onto provide examples of positive, negative and non-engagement in $\mathrm{HE}$ (Table I).
Table I: Examples of Positive, Negative and NonEngagement in students (Trower, 2010)

\begin{tabular}{llll}
\hline & $\begin{array}{l}\text { Positive } \\
\text { engagement }\end{array}$ & $\begin{array}{l}\text { Non- } \\
\text { engagement }\end{array}$ & $\begin{array}{l}\text { Negative } \\
\text { engagement }\end{array}$ \\
\hline Behavioural & $\begin{array}{l}\text { Attends } \\
\text { classes and } \\
\text { participates } \\
\text { with } \\
\text { enthusiasm }\end{array}$ & $\begin{array}{l}\text { Skips classes } \\
\text { with no good } \\
\text { reason or } \\
\text { excuses }\end{array}$ & $\begin{array}{l}\text { Boycotts or } \\
\text { actively } \\
\text { disrupts } \\
\text { classes }\end{array}$ \\
\hline Emotional & Interest & Boredom & Rejection \\
\hline Cognitive & $\begin{array}{l}\text { Meets or } \\
\text { exceeds } \\
\text { assignment } \\
\text { requirements }\end{array}$ & $\begin{array}{l}\text { Assignments } \\
\text { late, rushed or } \\
\text { absent }\end{array}$ & $\begin{array}{l}\text { Redefines } \\
\text { parameters } \\
\text { for } \\
\text { assignments }\end{array}$ \\
& & & a
\end{tabular}

The module team took the decision to try a new learning and teaching strategy to better engage students. It was thought that outcomes could be enhanced further by motivating students to engage with course content before class and increasing their active participation in-class. Students have a responsibility for their own learning and ultimately must decide the extent to which they engage. However, the HE institution also has a responsibility to try and promote and optimise positive engagement characteristics through curriculum design. The aim was to redesign the module in an attempt to better stimulate interest, involvement, and active participation from students and encourage them to take more responsibility for their learning in and out of class.

Ramsden (2003) describes learning as a qualitative change in the way people see, experience, understand, and conceptualise subject content during a learning activity; 'it is about what and how they learn rather than 'how much' they remember' (Ramsden, 2003: p.41).

To only try to 'cover the content' limits students to 'simply learning facts without the ability to apply their knowledge to solve novel problems' (DiCarlo, 2009: p.258). Focusing on content coverage without the ability to work with and apply it to problem-solve simply promotes what Marton and Säljö (1976) characterise as surface learning or, in other words, knowledge that is soon forgotten. If education is predominantly about learning facts, students will focus on memorising and rote learning, a skill that DiCarlo (2009) argues only teaches students how to take exams and prepares them for more education. Rote learning facts alone fails to develop problem-solving, critical thinking, communication and interpersonal skills 
they will need when they graduate. For learning to be effective it must be meaningful, purposeful and contextualised or it will fail to make a significant impact upon the learner (Weimer, 2002). To learn we must actively process and think about the relevance of the content to us, our future roles, and the world around us (Weimer, 2002). Learners need to know the importance of the content, how they will use it and what they will be able to 'do' with this new knowledge in order to foster 'deep learning' and optimise understanding (Marton \& Säljö, 1976; Weimer, 2002; Ramsden, 2003). When new learning is related to what the students already know and have experienced and actively work to organise and structure the content, then Marton and Saljo (1976) characterise the approach to learning as 'deep'. The learning and teaching strategy chosen was 'Team-based Learning' (TBL) as it was designed around the constructivist learning theory (Hrynchak \& Batty, 2012) and provided a motivational framework to both prepare for and attend classes. It also held students accountable for their actions, took a more learner-centred approach than previously, and presented students with problems to solve and make a collaborative decision together, which seemed to more closely reflect how they will work as a pharmacist.

In TBL, students work in permanent, diverse, teacherformed teams of five-seven students throughout the module. TBL takes a flipped classroom approach to learning where students are directed to prepare before classes by the readiness assurance process (RAP), which includes a summative individual readiness assurance test (iRAT) immediately followed by an identical team test (tRAT) to foster discussion, debate, and peer learning. Students and academic staff receive immediate feedback on team performance, allowing a focused class discussion on any troublesome course concepts. The final and longest part of a TBL unit is allocated to application exercises where teams engage with authentic, real-world problems, make collaborative team decisions, and justify their decisions to other teams during discussion and debate facilitated by an academic teacher (Michaelsen, Knight, \& Fink, 2002; Strayer, 2011; Sweet \& Michaelsen, 2012).

\section{Aim and Objective}

The aim of the study was to investigate students' experiences of using TBL using a mixed method approach and to evaluate any changes in assessment results.

\section{Objectives}

- Evaluate student feedback using a validated assessment tool

- Compare end-of-module assessment data from TBL cohort with results from a non-TBL cohort

- Identify and explain any common themes arising from student feedback from the module evaluation questionnaire

\section{Methods}

Ethics permission was sought and received for this project (EC2232). To achieve objective one, student feedback from one cohort $(n=83)$ was collected using the TeamBased Learning Student Assessment Instrument (TBL-SAI) (Mennenga, 2012), a validated tool that assessed students' accountability to their team, preference for, and satisfaction with TBL. Students considered 33 statements and assessed their level of agreement or disagreement using a standard Likert rating scale. The results were analysed using Mennenga's analysis tool (2012) to establish the degrees of self-accountability, preference for TBL and satisfaction with TBL. Responses were received from 75 of 83 students in the cohort.

For objective two, the end of module assessment results for two cohorts $(n=192)$ of students using TBL was compared with those from two cohorts of pre-TBL students ( $n=173)$.

Finally, for objective 3 the qualitative data from 113 comments on the 49 module evaluation questionnaires that were submitted were analysed using thematic analysis to identify any emerging key themes.

\section{Results}

Table II: Results from the TBL-SAI for the Consultation Skills module

\begin{tabular}{lcccc}
\hline Sub-scale & $\begin{array}{c}\text { Accountability } \\
\text { Score }\end{array}$ & $\begin{array}{c}\text { Preference } \\
\text { for TBL }\end{array}$ & $\begin{array}{c}\text { Satisfaction } \\
\text { with TBL }\end{array}$ & $\begin{array}{c}\text { Total } \\
\text { Score }\end{array}$ \\
\hline Range & $8-40$ & $16-80$ & $9-45$ & $33-165$ \\
\hline Neutral & 24 & 48 & 27 & 99 \\
\hline $\begin{array}{l}\text { Consultation } \\
\text { Skills } \\
\text { Module }\end{array}$ & 33.2 & 57.6 & 36.5 & 127.2 \\
\hline
\end{tabular}




\section{TBL-SAI}

Results from the TBL-SAI (Table II) suggested student preference for and satisfaction with TBL as a method for the delivery of teaching with all scores being above neutral. Additionally, the results also showed that students developed accountability to their team, a key pedagogical principle of TBL.

\section{Comparison of the end of module examination results}

A comparison of students' examination results (Table III) showed an increase of 8.5 percentage points (a rise of $13 \%)$ in the cohorts' learning using TBL $(n=192)$ compared with those being taught pre-TBL $(n=173)$.

Table III: End of Module Examination Results pre-TBL and post-TBL

\begin{tabular}{llll}
\hline Cohort & Semester 1 & Semester 2 & Mean \\
\hline $\begin{array}{l}\text { 2011/12 } \\
\text { pre-TBL }\end{array}$ & $\begin{array}{l}63 \% \\
(n=90)\end{array}$ & $\begin{array}{l}68 \% \\
(n=83)\end{array}$ & $\begin{array}{l}65.5 \% \\
(n=173)\end{array}$ \\
\hline 2012/13 TBL & $\begin{array}{l}68 \% \\
(n=104)\end{array}$ & $\begin{array}{l}80 \% \\
(n=88)\end{array}$ & $\begin{array}{l}74 \% \\
(n=192)\end{array}$ \\
\hline \% improvement & $+8 \%$ & $+17.6 \%$ & $+13 \%$ \\
\hline
\end{tabular}

Table IV: Themes arising from thematic analysis of written comments in Module Evaluation questionnaires

\begin{tabular}{|c|c|c|}
\hline $\begin{array}{l}\text { Area of } \\
\text { Enquiry }\end{array}$ & Codes & Theme \\
\hline $\begin{array}{l}\text { Positive } \\
\text { experiences }\end{array}$ & $\begin{array}{l}\text { Enjoyment, interactivity, } \\
\text { motivation, preparation, } \\
\text { attendance } \\
\text { Peer learning, pre-class } \\
\text { learning, structured learning, } \\
\text { spiral learning, effective } \\
\text { learning }\end{array}$ & $\begin{array}{l}\text { Enhanced active } \\
\text { engagement }\end{array}$ \\
\hline $\begin{array}{l}\text { Negative } \\
\text { experiences }\end{array}$ & $\begin{array}{l}\text { TBL rooms, length of } \\
\text { application exercise classes, } \\
\text { timings of application } \\
\text { exercises } \\
\text { Asking questions, summarising } \\
\text { the discussion, involving teams, } \\
\text { inconsistencies with staff } \\
\text { facilitation }\end{array}$ & $\begin{array}{l}\text { Timings and } \\
\text { logistics of } \\
\text { workshops } \\
\text { Improve staff } \\
\text { facilitation skills }\end{array}$ \\
\hline
\end{tabular}

The mean marks of the end-of-module examinations in the pre-TBL cohorts were compared with those in the post-TBL cohorts to ensure a like-for-like comparison. That is to say they do not take into account other summative elements of the module, for example coursework, the iRAT and tRAT results or peer evaluation results that were only present in the TBL cohort. The results show that the mean for both cohorts of students studying using TBL was higher than the two previous cohorts who learned using more traditional learning and teaching methods.

\section{Analysis of results from the module evaluation questionnaire}

Results from the analysis of the module evaluation questionnaire were positive with students enjoying the active learning, interactions, and challenging activities. Suggestions to improve included improving the time management of application exercises and better facilitation of discussion by academic staff (Table IV).

\section{Discussion}

The results from the TBL-SAI suggest that more students expressed a preference for TBL over previous methods and were largely satisfied with learning using TBL, however, this could be as a result of the pedagogy being new and novel to them. Positive student satisfaction with TBL has also been reported by other researchers using the TBL-SAI (Mennenga, 2013; Keshmiri et al., 2016; Branney \& Priengo-Hernandez, 2018; Carson \& Mennenga, 2019). TBL also appears to improve the accountability of individual students towards their team. This could possibly be explained by the fact that student teams are permanent, the use of assessed team activities that require team effort and individual preparation (in the tRAT), and through the use of a summative peer evaluation process. One could argue that developing team accountability is a sign of positive emotional engagement as students develop a sense of team belonging.

Thematic analysis of the qualitative data also supports the findings from the quantitative data with students' comments categorised under the theme of enhanced active engagement. This theme was formed from merging the codes enjoyment, interactivity, motivation, preparation, and attendance.

'The TBL sessions were so interactive and fun'

'Team-based learning was very good, it helped to study the module content better than having lectures' 
'TBL was a great way to interact with others'

'I thoroughly enjoyed learning using TBL and would recommend to all students'

'TBL works much better than group work, it encouraged me to study much earlier instead of leaving it all until the end of the year'

The increase in the mean student assessment marks after using TBL could be as a result of enhanced student motivation and engagement and the TBL approach taking deeper approaches to learning. An increase in assessment marks were also reported in other published studies (Zingone et al., 2010; Persky, 2012; Redwanski, 2012; Faezi et al., 2018).

Thematic analysis of the qualitative data in the feedback questionnaire suggests that TBL was an effective learning pedagogy for students. Merging codes peer learning, preclass learning, structured learning, spiral learning, effective learning led to the formation of the theme 'enhanced student learning':

II found that the TBL learning was a lot more effective for myself and that I learned more this way'

'Learning the content before coming to the workshops really worked for me and more people knew what the session was about. I felt as though we were learning more from the sessions'

'TBL should be carried on as it is a really good method of solidly embedding the content into our heads, which in effect made revision really easy'

'Team based learning was of huge help of me understanding topics as you can get other people's viewpoint'

'TBL was a really good opportunity to share understanding and discuss with peers and tutors'

Further thematic analysis of the qualitative data also revealed some difficulties students had and suggestions for improving their experiences of TBL. One of the themes that emerged was the 'timings and logistics of workshops' that emerged from the codes TBL rooms, length of application exercise classes, and timings of application exercises.

Students suggested that three-hour workshops are too long as they are tired by the end and lose their concentration. In TBL classes students are actively engaged in thinking, in discussing and in solving challenging problems. This form of learning is clearly tiring, probably more so than other less challenging forms of didactic learning, and so requires some thought to session planning. As a result of feedback, application exercise workshops were restricted to two hours.

'Three hours seems like a very long time, it is hard to focus by the end'

'Sessions are far too long, by the end of the three hours most of us are too tired and stop concentrating'

Another issue was that the timings of individual application exercises needed to be more tightly managed so that some teams were not waiting around for other teams for any significant length of time. The learning from this feedback is that each application exercise is timed and actively managed by the facilitators with the use of online timers on display. Notwithstanding this, when planning the entire workshop a degree of flexibility was included in case some application exercises take most of the cohort longer than predicted

'It does sometime seem like we run out of time to do all the application exercises'

\section{'TBL exercises should have a stricter time limit'}

Finally in this theme, the TBL classes were initially timetabled for a new room especially designed to promote active and collaborative learning, which was ideal for team discussions in the TRAT and completing the application exercises; however, they were not ideal for the initial assessed iRAT that individual students completed on their own. As these assessments were summative, then completing them in an environment designed for active discussion was not conducive to more formal test conditions. As a result, the Readiness Assurance Process (RAP) comprising of the iRAT, tRAT, appeals, and corrective feedback (instruction) now takes place in a different room to the application exercises.

'TBL room is not good for self assessments i.e. the iRat'

The final theme that emerged from the codes asking questions, summarising the discussion, involving teams, inconsistencies with staff facilitation was that it was clear that some of the teaching staff on the module needed some support and development on facilitating a TBL class. Facilitating learning through student discussion is likely to require a new skill set for many teachers, particularly those more used to delivering didactic teaching. The challenge is to draw out the discussion from different 
teams, call upon other student teams to answer questions, seek out the student expert in the room, and listen out for interesting intra-team discussions as the students are working on the problem that you can bring into the discussion during the facilitated inter-team discussion (Gullo, Ha \& Cook, 2015). Developing effective teacher facilitation skills for the TBL classroom are likely to be a key development need for teachers wishing to start using TBL for the first time. This will however depend on the teachers' past experiences of using active learning pedagogies.

\section{Limitations}

The results of two cohorts of students learning using TBL have been compared with two different cohorts of preTBL students. Each cohort is made up of different individuals who bring different experiences and abilities. It may be that the two TBL cohorts as a collective are of higher ability or bring enhanced experiences than the nonTBL cohort as a collective and that the higher examination performance would have occurred without the TBL intervention. The TBL-SAl was developed for United States' students in nursing and has had limited use in the United Kingdom to date. The sample size of two cohorts of students was relatively small therefore further, larger studies are recommended. The response rate from the module evaluation questionnaire was 26\% (49/192 responses) therefore is not necessarily representative of the cohorts.

\section{Conclusion}

TBL seems to have been well received by the pharmacy students studying this module who expressed satisfaction with and a preference for studying using TBL. Regularly working together in a team to accomplish shared goals seems to have developed accountability in students to their teams. However, it is not clear whether this is the result of extrinsic motivations due to peer evaluation and assessment marks or intrinsic motivation to support the team endeavour. More research on what motivates students in the TBL classroom is needed here. The final examination results for both TBL cohorts increased when compared with the previous two pre-TBL cohorts suggesting that TBL may incentivise students to study harder and/or take deeper approaches to learning which leads to increased examination performance. The qualitative written comments suggest that TBL was well received by students, however further research, possibly using student interviews or focus groups is necessary here to determine a deeper understanding of what elements they enjoyed best, how prepared they were to learn in this way, and what else could be improved. Effective planning, managing logistics, and staff development of facilitation skills are also important for teachers planning to use TBL in their modules or programmes.

\section{References}

Branney, J., \& Priego-Hernández, J. (2018). A mixed methods evaluation of team-based learning for applied pathophysiology in undergraduate nursing education. Nurse education today, 61, 127-133. https://doi.org/10.1016/i.nedt.2017.11.014

Carson, R., \& Mennenga, H. (2019). Team-Based Learning and the Team-Based Learning Student Assessment Instrument (TBLSAI): A Longitudinal Study of Master of Occupational Therapy Students' Changing Perceptions. American Journal of Occupational Therapy, 73(4). https://doi.org/10.5014/ajot. $\underline{2019.032623}$

Coates, H. (2005). The value of student engagement for higher education quality assurance. Quality in Higher Education, 11(1), 25-36. https://doi.org/10.1080/13538320500074915

DiCarlo, S.E. (2009). Too much content, not enough thinking, and too little fun!. Advances in Physiology Education, 33(4), 257-264. https://doi.org/10.1152/advan.00075.2009

Faezi, S.T., Moradi, K., Amin, A.G.R., Akhlaghi, M., \& Keshmiri, F. (2018). The effects of team-based learning on learning outcomes in a course of rheumatology. Journal of Advances in Medical Education \& Professionalism, 6(1), 22-30.

Fredricks, J.A., Blumenfeld, P.C., \& Paris, A.H. (2004). School engagement: Potential of the concept, state of the evidence. Review of Educational Research, 74(1), 59-109. https://doi.org/ $\underline{10.3102 / 00346543074001059}$

Gullo, C., Ha, T.C., \& Cook, S. (2015). Twelve tips for facilitating team-based learning. Medical Teacher, 37(9), 1-6. https:// doi.org/10.3109/0142159X.2014.1001729

Hidayat, L., Vansal, S., Kim, E., Sullivan, M., \& Salbu, R. (2012). Pharmacy student absenteeism and academic performance. American Journal of Pharmaceutical Education, 76(1), 8. https:// doi.org/10.5688/ajpe7618

Hrynchak, P., \& Batty, H. (2012). The educational theory basis of team-based learning. Medical Teacher, 34(10), 796-801. https:// doi.org/10.3109/0142159X.2012.687120

Hu, S., \& Kuh, G.D. (2002). Being (dis) engaged in educationally purposeful activities: The influences of student and institutional characteristics. Research in Higher Education, 43(5), 555-575. https://doi.org/10.1023/A:1020114231387 
Keshmiri, F., Rahmati, A., Amin, A.G., \& Faezi, T. (2016). Validating and Assessing the Reaction of Medical Students Toward Team-Based Learning. Acta Medica Iranica. Tehran: Tehran University of Medical Sciences, p.806

Kuh, G.D. (2009). What student affairs professionals need to know about student engagement. Journal of College Student Development, 50(6), 683-706. https://doi.org/10.1353/csd. $\underline{0.0099}$

Little, B., Locke, W., Scesa, A., \& Williams, R. (2009). Report to HEFCE on student engagement. HEFCE.

Marton, F., \& Säljö, R. (1976). On Qualitative Differences in Learning: I-Outcome and Process. British Journal of Educational Psychology, 46(1), 4-11. https://doi.org/10.1111/j.2044-8279. 1976.tb02980.x

Mennenga, H.A. (2012). Development and psychometric testing of the team-based learning student assessment instrument. Nurse Educator, 37(4), 168-172. https://doi.org/10.1097/NNE. Ob013e31825a87cc

Mennenga, H.A. (2013). Student Engagement and Examination Performance in a Team-Based Learning Course. Journal of Nursing Education, 52(8), 475-479. https://doi.org/ 10.3928/01484834-20130718-04

Persky, A.M. (2012). The impact of team-based learning on a foundational pharmacokinetics course. American Journal of Pharmaceutical Education, 76(2), 1-10. https://doi.org/10.5688/ ajpe76231

Ramsden, P. (2003). Learning to Teach in Higher Education. London: Routledge. https://doi.org/10.4324/9780203507711

Redwanski, J. (2012). Incorporating team-based learning in a drug information course covering tertiary literature. Currents in Pharmacy Teaching and Learning, 4(3), 202-206. https:// doi.org/10.1016/i.cptl.2012.04.004

Weimer, M. (2002). Learner-centered teaching: Five key changes to practice. San Francisco: Jossey-Bass

Zingone, M.M., Franks, A.S., Guirguis, A.B., George, C.M., Howard-Thompson, A., \& Heidel, R.E. (2010). Comparing teambased and mixed active-learning methods in an ambulatory care elective course. American Journal of Pharmaceutical Education, 74(9), 1-7. https://doi.org/10.5688/aj7409160 